\title{
Delivery routes in pregnancy with COVID-19 and the risk of intrapartum vertical transmission: a meta-analysis
}

Razmaeda Sarastry, Crismanto Layarta, Ussisti Aladini, Besari Adi Pramono

Check for updates

pISSN: 0853-1773 • elSSN: 2252-8083 https://doi.org/10.13181/mji.oa.214779 Med J Indones. 2021;30:116-22

Received: June 05, 2020

Accepted: February 05, 2021

Authors' affiliations:

Department of Obstetrics and Gynecology, Faculty of Medicine, Universitas Diponegoro, Semarang, Indonesia

\section{Corresponding author:}

Razmaeda Sarastry

Department of Obstetrics and

Gynecology, Faculty of Medicine,

Universitas Diponegoro, Jalan DR.

Sutomo No. 16, Randusari, Semarang,

Central Java 50244, Indonesia

Tel/Fax: +62-24-317650/+62-24-317650

E-mail: razmaeda@gmail.com

\begin{abstract}
BACKGROUND Mode of delivery has become an important highlight in managing pregnancy with coronavirus disease 2019 (COVID-19) due to the possible risk of viral transmission from mother to baby, especially during the peripartum period. This study aimed to review the mode of delivery and the possible risk of vertical transmission related to delivery routes in pregnant women with COVID-19.
\end{abstract}

METHODS Literature research was conducted using PubMed, Scopus, Embase, and EBSCO database with the following keywords: SARS-CoV-2, COVID-19, pregnancy, vertical transmission, and delivery. The extracted data were as follows: author, country, study design number of cases, maternal age, mode of delivery, and the SARS-CoV-2 status in neonates.

RESULTS Of 11 studies found, vaginal birth was reported in 218 cases (34.53\%) and cesarean delivery was reported in 385 women (65.47\%). The indication for cesarean delivery was majority due to COVID-19 related condition (53.61\%). In total, 8 neonates who confirmed positive for COVID-19 by real-time polymerase chain reaction assay were reported. The pooled odds ratio ( $95 \%$ confidence interval) for SARS-CoV-2-positive neonates in cesarean delivery compared with vaginal birth was $0.622(0.237-1.633)$ with $p=0.335$.

CONCLUSIONS Cesarean delivery is more common than vaginal delivery in patient with SARS-CoV-2 infection. Any delivery route is not related to possible risk of intrapartum vertical transmission, and cesarean delivery should be carried out based on the obstetric indication.

KEYWORDS COVID-19, delivery, meta-analysis, pregnancy, vertical transmission
Coronavirus disease 2019 (COVID-19) posed a novel challenge in the healthcare system team, including in the obstetrics and gynecology area. ${ }^{1-6}$ In the first quarter of the pandemic, there was limited information regarding the effect and management of COVID-19 in pregnant women. Due to the severity of the pandemic, well-designed studies on obstetrics are difficult to establish. Moreover, current recommendations mostly relied on the case reports and case series from the countries hit by the early wave of the pandemic. ${ }^{7-14}$ Additionally, most of the available guidelines are based on the previously known pathogenic coronavirus such as severe acute respiratory syndrome (SARS) and the Middle East respiratory syndrome. . $^{6,15}$

Nevertheless, there is no clear evidence on the optimal delivery time, preferred option for delivery mode, and low risk of vertical transmission through abdominal delivery. Valuable information to clinical practice may be gained from the studies conducted all over the world. The study aimed to analyze the provided information with specific concern on 
the delivery routes and possibility of intrapartum transmission of pregnancy with COVID-19.

\section{METHODS}

Literature research was conducted using several search engines, including PubMed, Scopus, Embase, and EBSCO from January 1, 2020, to September 30, 2020. The keywords used were SARS-CoV-2, COVID-19, pregnancy, vertical transmission, and delivery. The search strategy was as follows; ("2019-nCoV infection"[all] OR “coronavirus disease 2019"[all] OR “COVID-19 pandemic"[all] OR "2019-nCoV disease"[all] OR "2019 novel coronavirus disease"[all] OR “COVID-19"[all] OR "2019 novel coronavirus infection"[all] OR “coronavirus disease-19"[all] OR "severe acute respiratory syndrome coronavirus 2"[all] OR "SARS-CoV-2"[all]) AND (pregnancy [all] OR "pregnant women"[all] OR maternal [all] OR "prenatal care"[all]) AND (vertical transmission [all] OR "mother to child transmission"[all]). We also reviewed the lists of references of obtained articles to search for other relevant studies. Due to time constraints, one author (RS) conducted the literature search, reviewed the paper and extracted data on study characteristic, and selected maternal data, mode of delivery, and maternal-neonatal outcome, especially vertical transmission. Other authors (UA, $\mathrm{CL}$, and $\mathrm{BA}$ ) reviewed the papers and independently selected the eligible articles. The selection criteria include: case-control, cohort study, and case reports with subjects of pregnant women with COVID-19 who did delivery. Non-English language publications were not included in this review.

\section{Data extraction}

A patient, intervention, comparator, outcome, study design structure was used to create the study questions and the inclusion/exclusion criteria. The population of this study was the women with COVID-19 who were documented delivering their baby in the hospital. The question was: "What is the safe delivery route and the risk of vertical transmission in pregnant women with COVID-19?"

The extracted data from each study were: first author's last name, country, study design, number of pregnant women cases, maternal age, mode of delivery, and SARS-CoV-2 infection status in neonates. The meta-analysis was conducted following the
Preferred Reporting Items for Systematic Reviews and Meta-Analyses recommendation. ${ }^{16}$

\section{Statistical analysis}

Forest plots were used to describe the pooled prevalence, point ( $95 \%$ confidence intervals [Cl]) estimates, and in-between studies' variability. The inconsistency indicator (12) was chosen to show the relationship between true variability and overall variation, with low, medium, and high heterogeneity in case of the following values: $<25 \%, \geq 25-<50 \%$, and $\geq 50 \%$, respectively. Fixed and random-effects models were computed, keeping into consideration the expected between-study heterogeneity. Bias assessment plots and Egger weighted regression test methods were used to assess the publication bias. A p-value of $<0.05$ was considered statistically significant. The analyses were carried out with the statistical software of RevMan version 5.3 and MedCalc Software version 14 (MedCalc Software Ltd., Belgium).

\section{RESULTS}

\section{Study characteristics}

A flowchart of the literature search is presented in Figure 1. A total of 914 publications from PubMed (289), Scopus (297), Embase (252), EBSCO (76), and 11 appropriate studies (10 cohort studies and 1 case-control study) were selected. Studies reported pregnancy with confirmed COVID-19 was originated from China (5), United States (4), Italy (1), and United Kingdom (1).

A total number of 603 deliveries in pregnant women with confirmed COVID-19 were reported. Study characteristics and selected maternal characteristics were presented in Table 1 which comprised the maternal age, mode of deliveries, as well as the COVID-19 status in neonates stated in each study. ${ }^{17-27}$ The number of enrolled individuals ranged from 11 to 262. The mean (standard deviation) maternal age was 30.3 (1.5) years, ranging from 17 to 40 years. Delivery routes are presented in Table 1 . The vaginal delivery was seen in 218 cases (36.2\%), and cesarean delivery was reported in 385 women (63.8\%).

\section{Indication for cesarean section}

The indication for cesarean delivery was varied from obstetrical considerations to maternal related to COVID-19 infection. We analyzed all of the studies and 
Figure 1. The flow diagram in literature search for this review

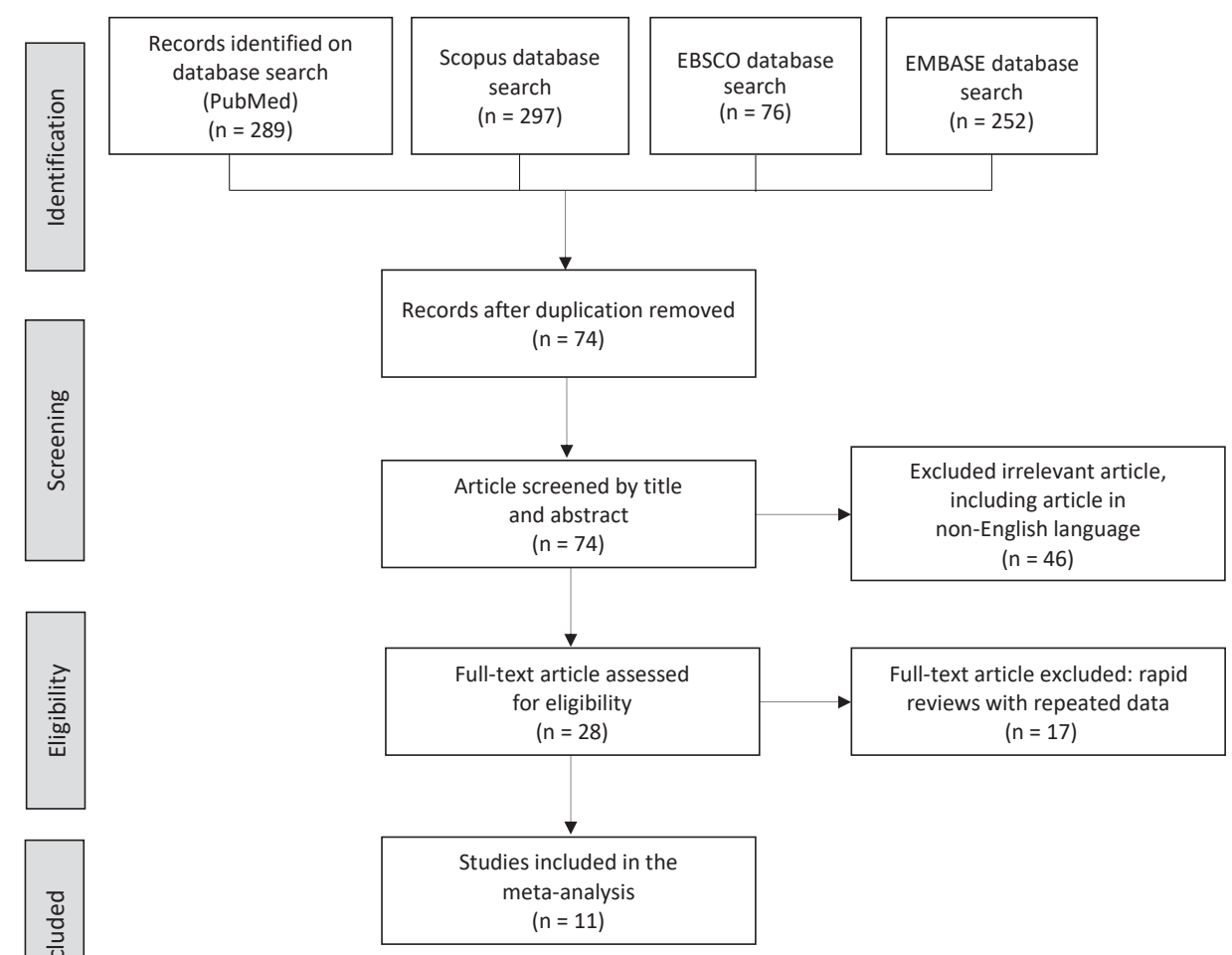

Table 1. Study characteristics, maternal age, delivery routes, and neonates infection status

\begin{tabular}{|c|c|c|c|c|c|c|c|}
\hline \multirow{3}{*}{ First author } & \multirow{3}{*}{ Sample size } & \multirow{3}{*}{ Study design } & \multirow{3}{*}{$\begin{array}{c}\text { Maternal age } \\
\text { range/mean (years) }\end{array}$} & \multicolumn{4}{|c|}{ Mode of delivery } \\
\hline & & & & \multicolumn{2}{|c|}{ Cesarean section } & \multicolumn{2}{|c|}{ Vaginal birth } \\
\hline & & & & $\begin{array}{l}\text { COVID-19 } \\
\text { cases }\end{array}$ & $\begin{array}{c}\text { Positive swab } \\
\text { on neonates }\end{array}$ & $\begin{array}{l}\text { COVID-19 } \\
\text { cases }\end{array}$ & $\begin{array}{l}\text { Positive swab } \\
\text { on neonates }\end{array}$ \\
\hline Ferrazzi, ${ }^{17}$ & 42 & Retrospective & $21-43$ & 18 & 0 & 24 & 1 \\
\hline Knight, $^{18}$ & 262 & Prospective & $18-40$ & 156 & 4 & 106 & 2 \\
\hline $\mathrm{Li}^{1}{ }^{19}$ & 16 & Case-control & $26-37$ & 14 & 0 & 2 & 0 \\
\hline $\mathrm{Liu}^{20}$ & 11 & Retrospective & $23-40$ & 10 & 0 & 1 & 0 \\
\hline $\mathrm{Nie}^{21}$ & 27 & Retrospective & $24-36$ & 22 & 1 & 5 & 0 \\
\hline Pierce-Williams, ${ }^{22}$ & 32 & Retrospective & 33 & 24 & 0 & 8 & 0 \\
\hline Prabhu, ${ }^{23}$ & 70 & Retrospective & $26-36$ & 32 & 0 & 38 & 0 \\
\hline Sahin, ${ }^{24}$ & 10 & Prospective & $17-40$ & 5 & 0 & 5 & 0 \\
\hline Yang, ${ }^{25}$ & 65 & Retrospective & $20-40$ & 52 & 0 & 13 & 0 \\
\hline Breslin, ${ }^{26}$ & 18 & Retrospective & 20-39 & 8 & 0 & 10 & 0 \\
\hline Yan, ${ }^{27}$ & 50 & Retrospective & 24-41 & 44 & 0 & 6 & 0 \\
\hline Total & 603 & & & 385 & 5 & 218 & 3 \\
\hline
\end{tabular}

calculated that more than half of the cesarean section was performed directly due to COVID-19 indication (53.61\%, $95 \% \mathrm{Cl}=35.794-70.977 ; p<0.001)$.

\section{Risk of transmission from mother to babies}

Overall, eight cases (1.62\%) suggested the possible intrapartum vertical transmission despite the delivery modes. It is shown by the positive result of real-time polymerase chain reaction (RT-PCR) assay of COVID-19 in neonates after birth (Figure 2). This analysis showed zero inconsistency level that refers to the low heterogeneity of the studies included. We also measured the possible bias that shows the relatively symmetrical plot between sides and a p-value of 0.7 


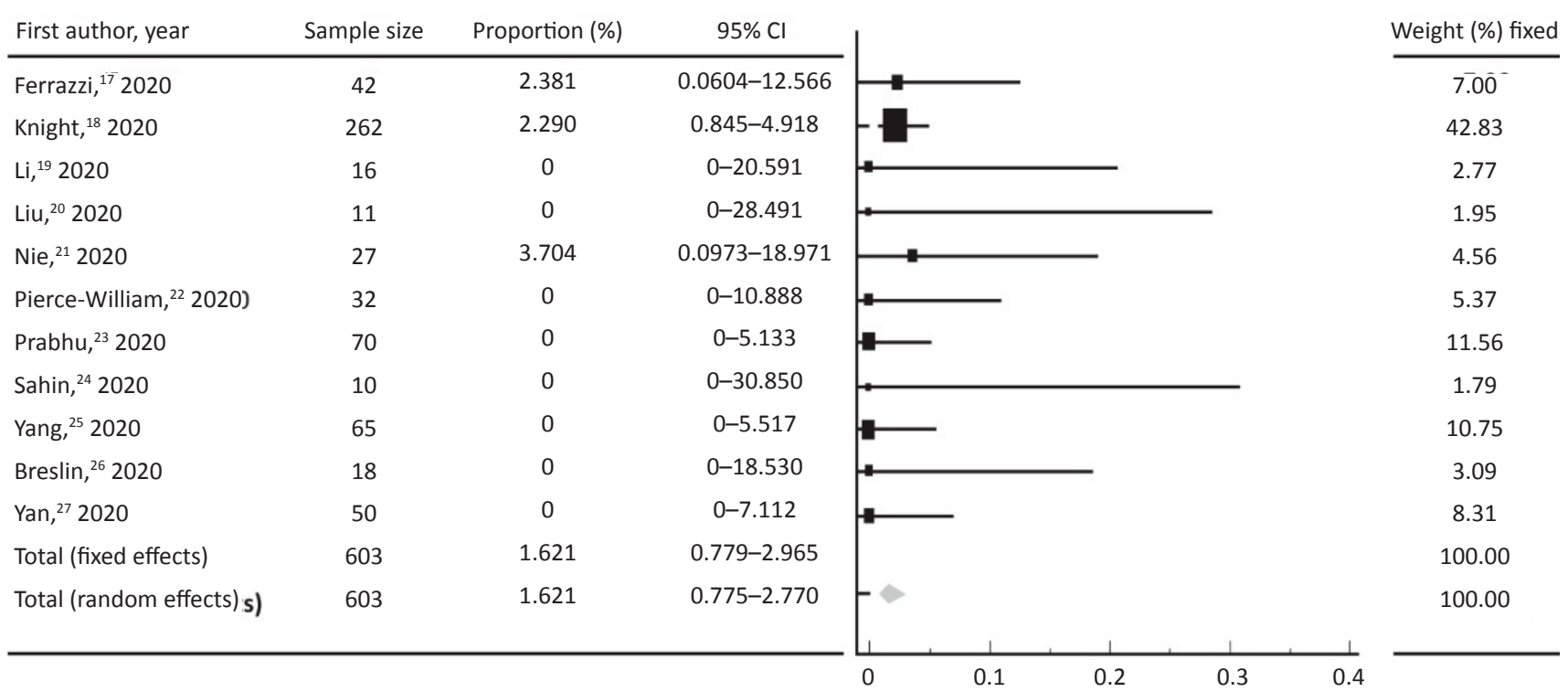

Figure 2. The pooled proportion of neonates with coronavirus disease 2019 (COVID-19) positive test on overall deliveries in pregnant women with COVID-19. Fixed effects, pooled proportions (95\% confidence interval $[\mathrm{Cl}])=1.621(0.775-2.770) ; \mathrm{I} 2(95 \% \mathrm{Cl})=0.00 \%$ $(0.00-35.22)$

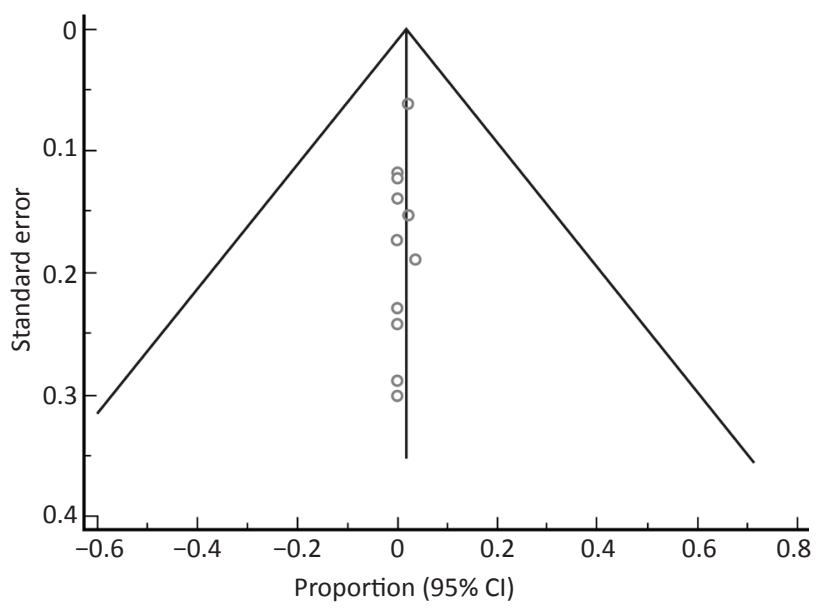

Figure 3. Funnel plot of coronavirus disease 2019 (COVID-19) positivity in neonates. Egger bias ( $95 \%$ confidence interval $[\mathrm{Cl}])=-0.2247(-1.4224-0.9730) ; p=0.6813$

(Figure 3). The non-significant $p$-value implicates a lower risk of publication bias.

We further analyzed whether different delivery routes may lower the risk of COVID-19 positivity in neonates. We compared both delivery methods and found that cesarean delivery did not reduce the risk of vertical transmission in neonates (odds ratio [OR] $=0.622,95 \% \mathrm{Cl}=0.237-1.633 ; p=0.335$ ) (Figure 4). We also analyzed the risk of publication bias by presenting the funnel plot (Figure 5), which showed a relatively symmetrical plot between studies with a $p$-value of 0.03 . The significant $p$-value might indicate the poor quality or methodology of the studies, hence increasing the risk of publication bias.

\section{DISCUSSION}

This systematic review and meta-analysis showed that mode of delivery did not associate with the risk of peripartum viral transmission in pregnant women with COVID-19. Mode of delivery has become one of the main focuses in managing pregnant women with COVID-19 due to the possibility of peripartum transmission of this highly infectious virus. Vertical transmission may occur in three different time points: during pregnancy via placenta, during delivery through direct contact with maternal blood or cervicovaginal secretion, and during the postpartum period via breastfeeding. ${ }^{14,28-30} \mathrm{~A}$ recent study on the placental pathology showed that the SARS-CoV-2 virus was found in maternal side of the placenta and influenced the placental vascular structure, hence interfered with its function..$^{29,31-34}$ However, those studies also described that none of the newborns were confirmed positive for COVID-19. ${ }^{28,31}$ Other studies showed that SARS-CoV-2 virus was not identified in amniotic fluid or cord. ${ }^{28-30,34-36}$

In total, we found 385 out of 603 deliveries were done using cesarean section and identified eight newborns had SARS-CoV-2 infection using RT$P C R$. Although vaginal delivery has a substantially 


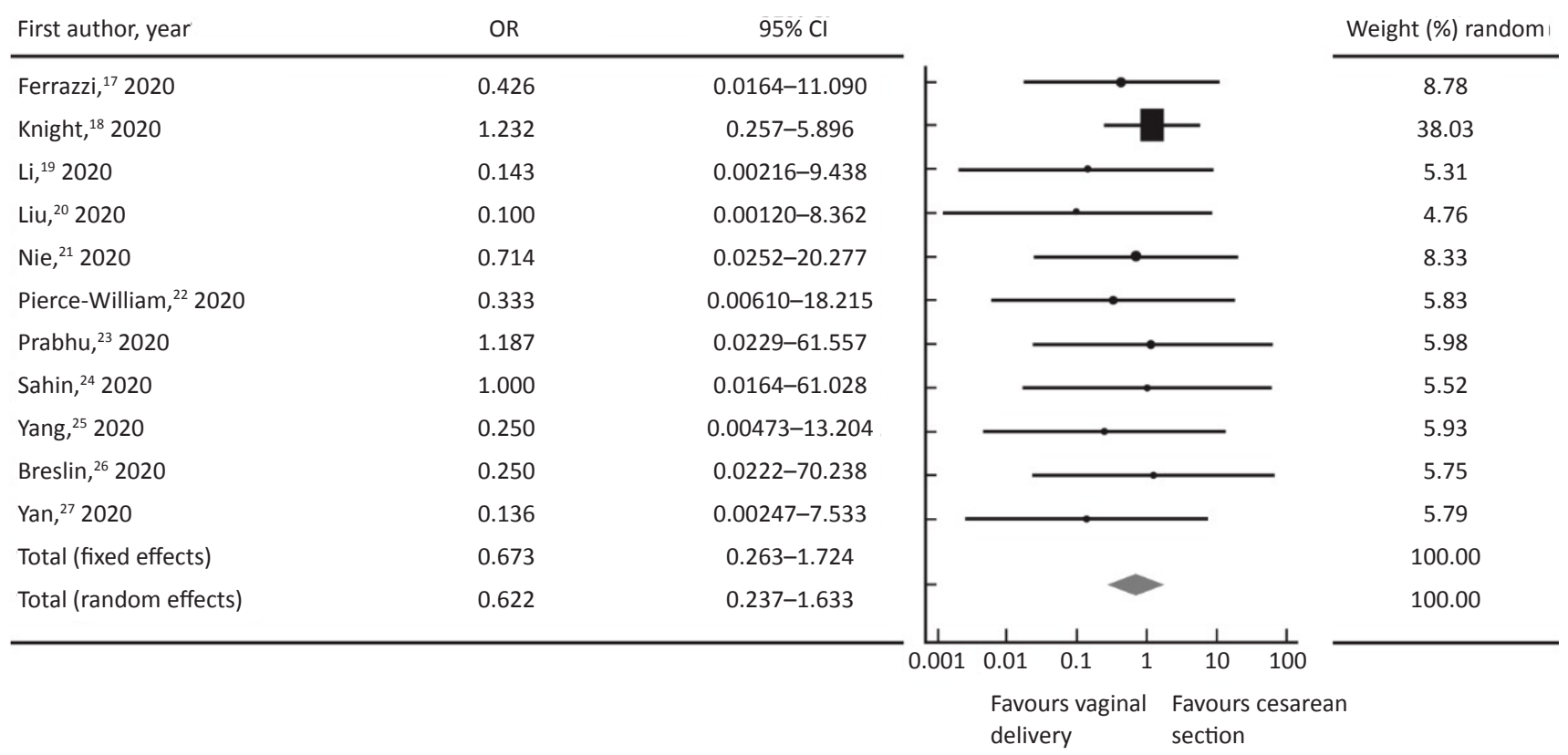

Figure 4. The odds ratio (OR) of vertical transmission possibility on the cesarean delivery in pregnant women with coronavirus disease 2019 (COVID-19). Random effects, pooled OR (95\% confidence interval $[\mathrm{Cl}])=0.622(0.237-1.633) ; \mathrm{p}=0.335 ; \mathrm{I} 2(95 \% \mathrm{Cl})=$ $0.00 \%(0.00-0.00)$

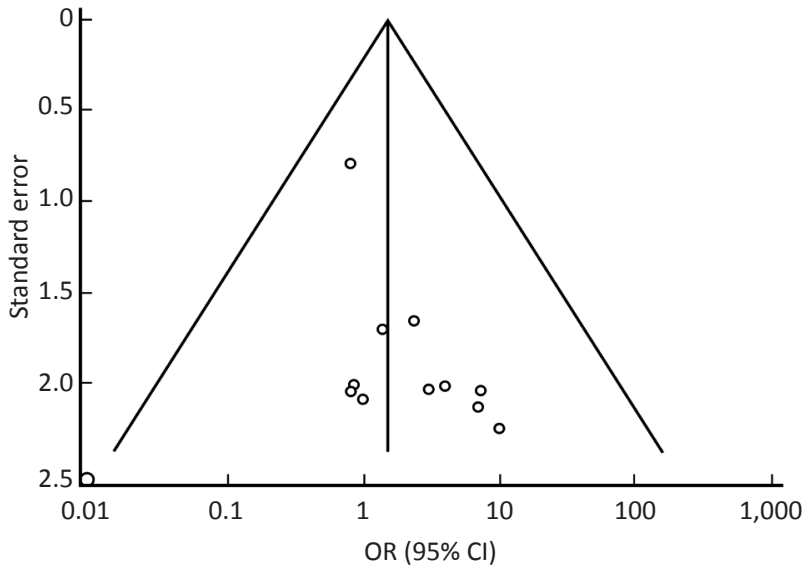

Figure 5. Funnel plot of odds ratio (OR) on the risk of vertical transmission according to mode of delivery. Egger bias (95\% confidence interval $[\mathrm{Cl}])=0.9829(0.1680-1.7978) ; p=0.0233$

higher risk of neonatal contact with cervicovaginal secretion, ${ }^{12,17,28,34}$ the result showed that vaginal delivery did not significantly increase the risk of neonates having SARS-CoV-2 infection. Meanwhile, the cesarean section has been the primary choice for the delivery mode in women with confirmed COVID-19. ${ }^{10,22,25,27,34,37}$ The indication for these cesarean sections was COVID-19 (53.6\%). A study reported that COVID-19 had been an indication for cesarean section in their institution. ${ }^{24}$ This review reassures that both delivery modes do not increase the risk of intrapartum viral vertical transmission. It supports the latest recommendation that SARS-CoV-2 infection should not interfere in the birth mode decision unless there is worsening of the cardiopulmonary condition. The recommendation also stated that every delivery of pregnant women with confirmed COVID-19 should be performed according to suitable personal protective equipment. ${ }^{31}$

A planned vaginal delivery needs close contact and a long monitoring duration of the mother and the fetus. Although these can be normally done by obstetricians or midwives, it is difficult to be performed during the pandemic. It is also challenging to do this vaginal delivery while prioritizing the safety of the healthcare workers. Moreover, labor wards in Indonesia had not been prepared with negative-pressure ventilation. Trained personnel were also insufficiently available. Therefore, the cesarean delivery was often chosen to limit the exposure and anticipate the unexpected complication of COVID-19 during labor.

This study addresses a crucial research question in making clinical decisions. The rationalization to do a cesarean section is deemed to protect the healthcare workers' safety but not to prevent the risk of vertical infection. However, COVID-19 should not be justified as the sole indication for performing a cesarean section. In minimizing potential bias, we restricted the metaanalysis to cohort studies and selected one case-control to provide a clearer methodology. We also reported 
the bias analysis presented in the funnel plot in the ORs calculation, which showed zero inconsistency hence low heterogeneity.

This systematic review also has several limitations. The sample sizes of the studies were relatively small and highly varied between studies because the subject recruitment was performed conveniently due to this pandemic situation. Most of the selected studies were retrospective. A broad scope of studies included in this review might address slightly different research questions with a wide range of methodological precision.

In conclusion, this review showed that cesarean delivery is more common than vaginal delivery in patients with confirmed COVID-19. However, the vertical transmission in both delivery methods is similar. Therefore, it is reassured that decision of the delivery route should not be influenced merely by the presence of SARS-CoV-2 infection in the mother. Obstetric indication is an important consideration to achieve favorable maternal and neonatal outcomes.

\section{Conflict of Interest}

The authors affirm no conflict of interest in this study.

\section{Acknowledgment}

The authors would like to thank to Fetomaternal Division of Obstetrics and Gynecology Department, Universitas Diponegoro.

\section{Funding Sources}

None.

\section{REFERENCES}

1. World Health Organization. Novel coronavirus (2019-nCoV): situation report-15 [Internet]. 2020 [cited 2020 May 18]. Available from: https://www.who.int/docs/default-source/ coronaviruse/situation-reports/20200204-sitrep-15-ncov.pdf.

2. Mascio DD, Khalil A, Saccone G, Rizzo G, Buca D, Liberati M, et al. Outcome of coronavirus spectrum infections (SARS, MERS, COVID-19) during pregnancy: a systematic review and metaanalysis. Am J Obstet Gynecol MFM. 2020;2(2):100107.

3. Alserehi $\mathrm{H}$, Wali G, Alshukairi A, Alraddadi B. Impact of Middle East respiratory syndrome coronavirus (MERS-CoV) on pregnancy and perinatal outcome. BMC Infect Dis. 2016;16:105.

4. Wong SF, Chow KM, Leung TN, Ng WF, Ng TK, Shek CC, et al. Pregnancy and perinatal outcomes of women with severe acute respiratory syndrome. Am J Obstet Gynecol. 2004;191(1):292-7.

5. Yudin MH, Steele DM, Sgro MD, Read SE, Kopplin P, Gough KA. Severe acute respiratory syndrome in pregnancy. Obstet Gynecol. 2005;105(1):124-7.

6. Maxwell C, Mcgeer A, Fan K, Tai KF, Sermer M, Farine D, et al. Management guidelines for obstetric patients and neonates born to mothers with suspected or probable severe acute respiratory syndrome (SARS). J Obstet Gynaecol Can. 2009;31(4):358-64.

7. Wang X, Zhou Z, Zhang J, Zhu F, Tang Y, Shen X. A case of 2019 novel coronavirus in a pregnant woman with preterm delivery. Clin Infect Dis. 2020;71(15):844-6.
8. Wu Y, Liu C, Dong L, Zhang C, Chen Y, Liu J, et al. Coronavirus disease 2019 among pregnant Chinese women: case series data on the safety of vaginal birth and breastfeeding. BJOG. 2020;127(9):1109-15.

9. Zhu H, Wang L, Fang C, Peng S, Zhang L, Chang G, et al. Clinical analysis of 10 neonates born to mothers with 2019-nCoV pneumonia. Transl Pediatr. 2020;9(1):51-60.

10. Liu H, Liu F, Li J, Zhang T, Wang D, Lan W. Clinical and CT imaging features of the COVID-19 pneumonia: focus on pregnant women and children. J Infect. 2020;80(5):e7-13.

11. Wang S, Guo L, Chen L, Liu W, Cao Y, Zhang J, et al. A case report of neonatal 2019 coronavirus disease in China. Clin Infect Dis. 2020;71(15):853-7.

12. Iqbal SN, Overcash R, Mokhtari N, Saeed H, Gold S, Auguste T, et al. An uncomplicated delivery in a patient with covid-19 in the United States. N Engl J Med. 2020;382(16):e34.

13. Lee DH, Lee J, Kim E, Woo K, Park HY, An J. Emergency cesarean section performed in a patient with confirmed severe acute respiratory syndrome coronavirus-2 -a case report. Korean J Anesthesiol. 2020;73(4):347-51.

14. Chen Y, Peng H, Wang L, Zhao Y, Zeng L, Gao H, et al. Infants Born to mothers with a new coronavirus (COVID-19). Front Pediatr. 2020;8:104.

15. World Health Organization. Interim surveillance recommendations for human infection with novel coronavirus [Internet]. 2020;(June):1-4. Available from: http://www.who.int/csr/disease/coronavirus_infections/ InterimRevisedSurveillanceRecommendations nCoVinfection_18Mar13.pdf.

16. Moher D, Liberati A, Tetzlaff J, Altman DG, PRISMA Group. Preferred reporting items for systematic reviews and meta-analyses: the PRISMA statement. PLoS Med. 2009;6(7):e1000097.

17. Ferrazzi E, Frigerio L, Savasi V, Vergani P, Prefumo F, Barresi S, et al. Vaginal delivery in SARS-CoV-2 infected pregnant women in Northern Italy: a retrospective analysis. BJOG. 2020;127(9):1116-21.

18. Knight M, Bunch K, Vousden N, Morris E, Simpson N, Gale C, et al. Characteristics and outcomes of pregnant women admitted to hospital with confirmed SARS-CoV-2 infection in UK: national population based cohort study. BMJ. 2020;369:m2107.

19. Li N, Han L, Peng M, Lv Y, Ouyang Y, Liu K, et al. Maternal and neonatal outcomes of pregnant women with coronavirus disease 2019 (COVID-19) pneumonia: a case-control study. Clin Infect Dis. 2020;71(16):2035-41.

20. Liu D, Li L, Wu X, Zheng D, Wang J, Yang L, et al. Pregnancy and perinatal outcomes of women with coronavirus disease (covid-19) pneumonia: a preliminary analysis. AJR Am J Roentgenol. 2020;215(1):127-32.

21. Nie R, Wang SS, Yang Q, Fan CF, Liu YL, He WC, et al. Clinical features and the maternal and neonatal outcomes of pregnant women with coronavirus disease 2019. MedRxiv. 2020.

22. Pierce-Williams RA, Burd J, Felder L, Khoury R, Bernstein PS, Avila $\mathrm{K}$, et al. Clinical course of severe and critical coronavirus disease 2019 in hospitalized pregnancies: a United States cohort study. Am J Obstet Gynecol MFM. 2020;2(3):100134.

23. Prabhu M, Cagino K, Matthews KC, Friedlander RL, Glynn SM, Kubiak JM, et al. Pregnancy and postpartum outcomes in a universally tested population for SARS-CoV-2 in New York City: a prospective cohort study. BJOG. 2020;127(12):1548-56.

24. Sahin D, Tanacan A, Erol SA, Anuk AT, Eyi EG, Ozgu-Erdinc AS, et al. A pandemic center's experience of managing pregnant women with COVID-19 infection in Turkey: a prospective cohort study. Int J Gynaecol Obstet. 2020;151(1):74-82.

25. Yang R, Mei H, Zheng T, Fu Q, Zhang Y, Buka S, et al. Pregnant women with COVID-19 and risk of adverse birth outcomes and maternal-fetal vertical transmission: a population-based cohort study in Wuhan, China. BMC Med. 2020;18:330.

26. Breslin N, Baptiste C, Gyamfi-Bannerman C, Miller R, Martinez $\mathrm{R}$, Bernstein K, et al. Coronavirus disease 2019 infection among 
asymptomatic and symptomatic pregnant women: two weeks of confirmed presentations to an affiliated pair of New York City hospitals. Am J Obstet Gynecol MFM. 2020;2(2):100118.

27. Yan J, Guo J, Fan C, Juan J, Yu X, Li J, et al. Coronavirus disease 2019 in pregnant women: a report based on 116 cases. Am J Obstet Gynecol. 2020;223(1):111.e1-14.

28. Dong L, Tian J, He S, Zhu C, Wang J, Liu C, et al. Possible vertical transmission of SARS-CoV-2 From an infected mother to her newborn. JAMA. 2020;323(18):1846-8.

29. Chen H, Guo J, Wang C, Luo F, Yu X, Zhang W, et al. Clinical characteristics and intrauterine vertical transmission potential of COVID-19 infection in nine pregnant women: a retrospective review of medical records. Lancet. 2020;395(10226):809-15.

30. Shanes ED, Mithal LB, Otero S, Azad HA, Miller ES, Goldstein JA. Placental pathology in COVID-19. Am J Clin Pathol. 2020;154(1):23-32.

31. Society for Maternal-Fetal Medicine and Society for Obstetric Anesthesia and Perinatology. Labor and delivery COVID-19 considerations. 2020 [updated 2020 Oct 9; cited 2020 Jul 6]. Available from: https://s3.amazonaws.com/cdn.smfm. org/media/2542/SMFM-SOAP_COVID_LD_Considerations_- revision 10-9-20 (final).pdf

32. Baud D, Greub G, Favre G, Gengler C, Jaton K, Dubruc E, et al. Second-trimester miscarriage in a pregnant woman with SARS CoV-2 infection. JAMA. 2020;323(21):2198-200.

33. Fan C, Lei D, Fang C, Li C, Wang $M$, Liu $Y$, et al. Perinatal transmission of COVID-19 associated SARS-CoV-2: should we worry? Clin Infect Dis. 2020:ciaa226.

34. Li Y, Zhao R, Zheng S, Chen X, Wang J, Sheng X, et al. Lack of vertical transmission of severe acute respiratory syndrome coronavirus 2, China. Emerg Infect Dis. 2020;26(6):1335-6.

35. Zeng H, Xu C, Fan J, Tang Y, Deng Q, Zhang W, et al. Antibodies in infants born to mothers with COVID-19 pneumonia. JAMA. 2020;323(18):1848-9.

36. Yu N, Li W, Kang Q, Xiong Z, Wang S, Lin X, et al. Clinical features and obstetric and neonatal outcomes of pregnant patients with COVID-19 in Wuhan, China: a retrospective, single-centre, descriptive study. Lancet Infect Dis. 2020;20(5):559-64.

37. Zhang $\mathrm{Y}$, Chen R, Wang J, Gong $\mathrm{Y}$, Zhou Q, Cheng $\mathrm{HH}$, et al. Anaesthetic managment and clinical outcomes of parturients with COVID-19: a multicentre, retrospective, propensity score matched cohort study. MedRxiv. 2020. 